\title{
Chromatographic Profiles of Umami Fractions from Indonesian Commercial Salty Soy Sauce
}

\author{
Hanifah Nuryani Lioe ${ }^{1 *}$, Diana Ayu Nindita ${ }^{1)}$, Warsono El Kiyat ${ }^{1)}$, Annisa Istiqamah ${ }^{1)}$
}

\author{
1) Department of Food Science and Technology, Faculty of Agricultural Engineering and Technology, IPB University \\ (Bogor Agricultural University), Darmaga, Bogor 16680 \\ ${ }^{*}$ Correspondence Email: hanifahlioe@apps.ipb.ac.id
}

\begin{abstract}
Salty soy sauce subjected in this study is a variety of commercial soy products in Indonesia. Chromatographic profiles linked to taste dilution analysis of the soy sauce were analyzed by Sephadex G-15 gel filtration chromatography followed by RP-HPLC. The results showed that there were 4 umami fractions (Fractions I - IV) obtained by Sephadex G-15 separation. Chromatographic profiles at $254 \mathrm{~nm}$ could show the differentiation of the four fractions and then their RP-HPLC profiles were proven to be different from each other. Fraction III which contained $65 \%$ of the soy sauce dry matters, had the highest umami intensity with umami TD factor of 256 , meanwhile, this fraction was tasted salty due to the salt contained in the soy sauce. Fraction III was dominated by the later peaks in the RP-HPLC chromatogram, which was more hydrophobic. The hydrophobic components were commonly tasted bitter, perhaps in the commercial salty soy sauce, the taste interaction between the umami and bitter components might have occurred.
\end{abstract}

Keywords: nonvolatile components; RP-HPLC profile; salty soy sauce; taste dilution analysis, hydrophobic components

\section{INTRODUCTION}

Soy sauce is a seasoning that has a strong savory or umami taste. Indonesian soy sauce is produced from black or yellow soybeans through two stages of fermentation (Apriyantono et al., 1999). The first fermentation stage is mold fermentation and the second stage is moromi or brine fermentation at a relatively high salt concentration (approximately $17 \% \mathrm{w} / \mathrm{v}$ of natrium chloride in final salty soy sauce product) (Röling et al., 1994; Apriyantono et al., 2004). There are two types of commercial soy sauce in Indonesia, namely sweet soy sauce or kecap manis and salty soy sauce or kecap asin. Salty soy sauce is produced by cooking the moromi, without sugar added, while sweet soy sauce is cooked with a high amount of caramelized sugar (Röling et al., 1994; Röling et al., 1996; Apriyantono et al., 2004).

Five basic tastes, acid, sweet, bitter, salty, and umami; were already identified. The non-volatile compounds have been known to be the responsible compounds for the five basic tastes due to their capability to interact with taste receptors located on the taste buds of the tongue (Belitz et al., 2009). The most interesting component is that resulted from protein hydrolysis by the action of proteases, i.e. amino acids and small peptides with molecular weights less than $500 \mathrm{Da}$, which were usually present in the low molecular weight fraction (Lioe et al., 2004; Lioe et al., 2007; Lioe et al., 2018). It has been known that amino acids and peptides have many tastes: sweet, bitter, and umami tastes (Kato et al., 1989). Free amino acids especially have been proved to contribute to several fermented soy products including Japanese soy sauce (shoyu), Indonesian soy sauce made from yellow soybeans (Lioe et al., 2004; Lioe et al., 2007) and Korean soy sauce (Kim et al., 2017). Studies on the umami flavoring compounds in several soy sauces indicated that hydrophilic free amino acids, especially free L-glutamic acid, L-threonine, L-serine, and other amino acids, and hydrophilic peptides of less than $500 \mathrm{Da}$ molecular weights were thought to have an influence on the umami taste intensity of soy sauce (Apriyantono et al., 2004; Lioe et al., 2004; Lioe et al., 2007; Kim et al., 2017; Lioe et al., 2006). Hydrophobic free amino acids such as L-leucine, L-isoleucine, L-valine, and L-phenylalanine were also found relatively abundant in Japanese soy sauce (Lioe et al., 2006; Lioe et al., 2007) as well as Indonesian soy sauce (Lioe et al., 2004) which could contribute to the umami taste characteristics of soy sauce.

Commercial soy sauce is usually made from black soybeans (Röling et al., 1994; Röling et al., 1996). However, its chromatographic profiles as well as taste intensities of commercial salty soy sauce, which has higher perceived umami taste than commercial sweet soy sauce, were not investigated yet. This study is important to know the intensities of the umami taste of Indonesian commercial soy sauce compared to other soy sauces already investigated previously, and to know the characteristic of components in its fraction through HPLC profiles. The objective of this research was to separate the fractions of commercial salty soy sauce by gel filtration chromatography and to know the taste characteristics through umami taste dilution analysis (TDA) as well as to observe the reversed-phase high-performance liquid chromatography (RP-HPLC) profiles of the obtained fractions, which could predict the hydrophobicity of the components in peaks with later retention times. RP-HPLC is commonly used for the investigation of taste components in food, which are nonvolatile (Dang et al., 2015; Lioe et al., 2006; Lioe et al., 2018). 


\section{MATERIALS AND METHODS \\ Materials}

The materials used were salty soy sauces, Angsa brand name produced by Refinery Kecap Co., Medan, Indonesia and $\mathrm{ABC}$ brand name produced by $\mathrm{ABC}$ Heiz Indonesia Co., Jakarta, Indonesia, which represented the commercial salty soy sauces marketed in Java and Sumatra Islands. Packed material of gel filtration chromatography was Sephadex G-15 (GE Healthcare, USA) with a specification of $\mathrm{pH} 2-13$ range, wet particle size $60-80 \mu \mathrm{m}$, molecular weight separation range of less than $1500 \mathrm{Da}$. Aquadest was used for gel filtration, however demineralized water was used for HPLC analysis. $\mathrm{NaCl}$, acetonitrile, monosodium glutamate (MSG), sucrose, citric acid, and caffeine were of analytical grade (assays more than 99\%) from Merck (Germany). Mineral water (AQUA, Indonesia) was used throughout the sensory analysis.

\section{Fractionation by gel filtration chromatography}

A total of $5.0 \mathrm{~mL}$ of each brand of salty soy sauce was incorporated into Sephadex G-15 chromatography gel filtration column at $27^{\circ} \mathrm{C}$ and a flow rate of $42 \mathrm{~mL} / \mathrm{h}$ with aquadest as eluent to 60 tubes of each of $7.5 \mathrm{~mL}$ using a fraction collector SF-100 (Toyo, Japan). This method referred to Istiqamah et al. (2019). The UV absorbance of the eluate was then measured at wavelengths of 214 and 254 nm using a UV-Vis 160 spectrophotometer (Shimadzu, Japan). The peaks observed through the obtained chromatogram were used for consideration to divide the soy sauce fractions. The eluate in the tubes from the same peak was combined into one fraction. The pooled eluates were freeze-dried by a freeze dryer (model FDU-1100, EYELA, Japan) to obtain a dry fraction. The dry matters in each dry fraction were then weighed and dissolved with aquadest up to the same volume of $5.0 \mathrm{~mL}$, as the initial soy sauce volume. These fractions were further characterized by HPLC and by sensorial taste dilution analysis (TDA) described below. The experiment was performed in duplicate.

\section{RP-HPLC profile}

The four fractions, I to IV, obtained by Sephadex G-15 separation were diluted using Milli-Q water with dilution factors, 100, 500, 1000, and 2, respectively, and then injected into RP-HPLC-MWD. The RP-HPLC analysis was performed using a C18 column (i.d. $4.6 \mathrm{~mm} \times 150$ $\mathrm{mm}, 5 \mu \mathrm{m}$ particle size). Isocratic elution at the ambient temperature of acetonitrile in Milli-Q water $(20 \%)$ and injection volume at $20 \mu \mathrm{L}$ was applied. The RP-HPLC was operated at room temperature. This method referred to Tamam et al. (2019). Detection was performed with a multi-wavelength detector (MWD) at $214 \mathrm{~nm}$ and 254 $\mathrm{nm}$ UV wavelengths. Detection at $254 \mathrm{~nm}$ was to observe whether the peaks containing aromatic group or not. The peak profiles obtained were then evaluated and compared with the TDA test results.

\section{Taste dilution analysis}

Taste dilution analysis (TDA) was carried out in the previous study (Frank et al., 2001; Ottinger and Hofmann,
2003). This analysis was conducted to determine the best taste dilution (TD) factor in describing sample flavor.

\section{Panelist selection and training}

Seven subjects (ages 24 to 28 years) from Department of Food Science and Technology, Bogor Agricultural University, Food Science master program, were participated in the panelists selection and training by a triangle test (Carpenter et al., 2000) using the following taste solution in mineral water ( $\mathrm{pH} 7$ by using litmus paper $\mathrm{pH} 1$ to 14 test strips), at nearly above taste threshold concentration: 12.6 $\mathrm{mM}$ sucrose for sweet taste; $12 \mathrm{mM} \mathrm{NaCl}$ for saltiness; monosodium glutamate (MSG) $2.1 \mathrm{mM}$ for umami taste; $0.8 \mathrm{mM}$ citric acid for sour taste; and caffeine $0.5 \mathrm{mM}$ for bitter taste (Ottinger and Hofmann, 2003). Panelists were required to taste $1 \mathrm{~mL}$ of each solution arranged in 3 sets of triangle test with mineral water. Re-tasting was not allowed. Sensory evaluation was done in a room at 25 to $26^{\circ} \mathrm{C}$. The panelist who could answer as much as $80 \%$ or more of 15 triangle sets correctly, was selected. Three panelists were selected and then trained for the determination of taste dilution (TD) factor using a soy sauce as a sample following the same procedures as below.

Determination of taste dilution (TD) factor by taste dilution analysis (TDA). The Sephadex G-15 gel filtration fractions were evaluated by three trained panelists. The samples were dissolved following the dilution factor $1,2,4,8,16$, $32,64,128,256,512$, and so on until it reached two or three levels above the dilution factor, which is no different taste between the diluted sample and the two mineral water was detected by the panelists. The TDA was done by tasting 1 $\mathrm{mL}$ of sample solution using a triangle test with mineral water. Panelists were asked to detect the taste difference between samples and 2 blanks (mineral water). When a different taste could just be detected in dilution, the panelist was asked to describe the taste (sweet, salty, umami, sour, bitter) according to the test in panelist selection and training. The TD factor is the dilution at which a recognized different taste was just detected. The umami dilution factor (TD factor of umami) is reported for results and discussion to trace the umami fraction of salty soy sauce. 


\section{RESULT AND DISCUSSION \\ Separated gel filtration fractions and their sensory \\ characteristics}
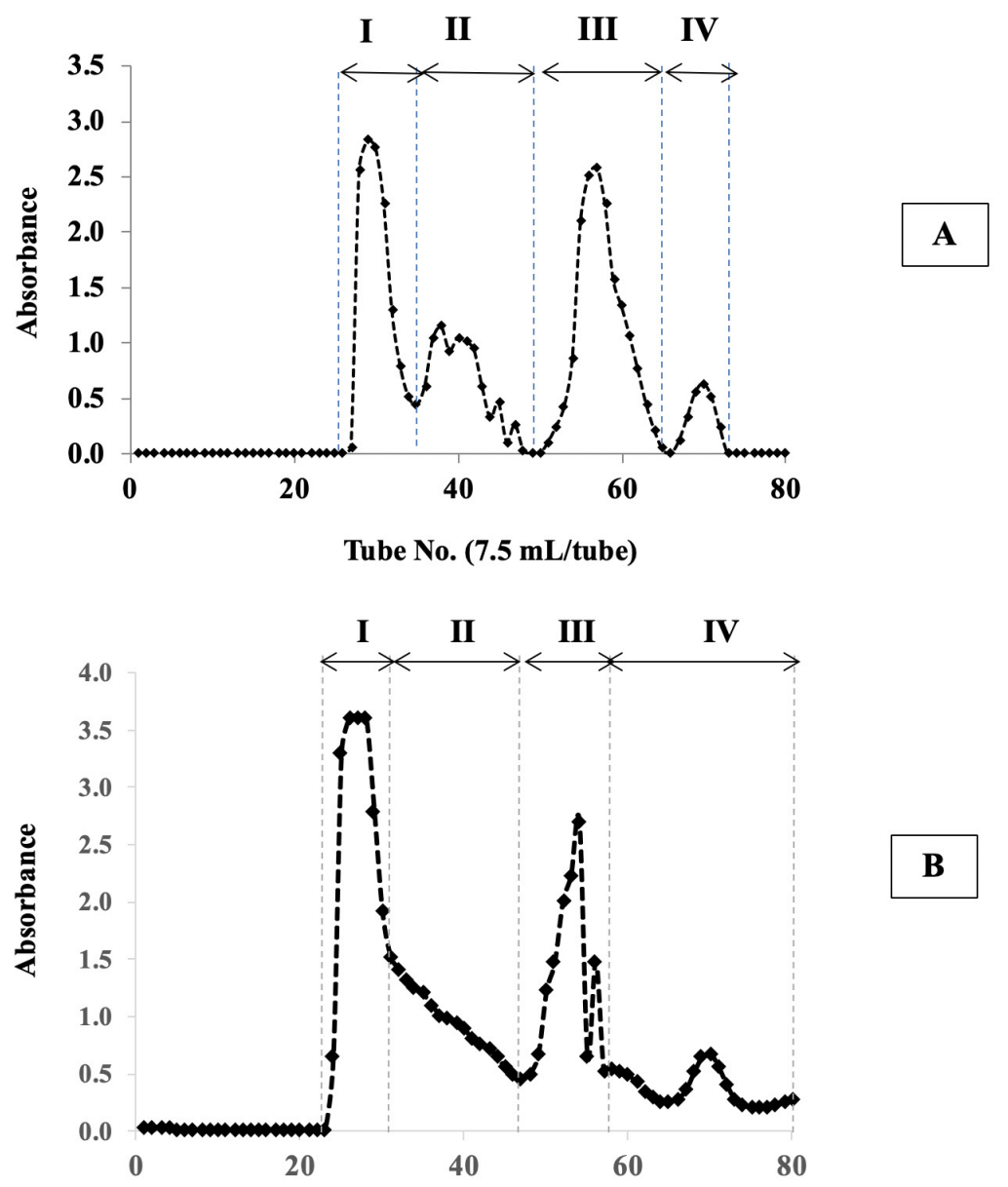

Tube No. (7.5 mL/tube)

Figure 1 - Chromatogram of commercial salty soy sauce fractions of: A. Angsa brand and B. ABC brand of Indonesian products, with molecular weights (MW) of less than 1500 Da obtained by gel filtration chromatography. The fractionation was performed on a Sephadex G-15 column $(2.5 \times 60 \mathrm{~cm})$ at $25-26{ }^{\circ} \mathrm{C}$ (Air-conditioned room) and a flow rate of $42-43 \mathrm{~mL} / \mathrm{h}$ with aquadest as an eluant. The sample volume was $5.0 \mathrm{~mL}$. Absorbance was measured at $254 \mathrm{~nm}$.

The low molecular weights (less than $1500 \mathrm{Da}$ ) fractions of salty soy sauces were obtained by using Sephadex G-15 gel filtration, as the specification of this gel for filtering compounds less than $1500 \mathrm{Da}$. The separation using this gel was based on the molecular size and the hydrophobic interaction between the compounds and the gel matrix (dextran with epichlorohydrin cross-links). There were four gel filtration fractions, Fractions I to IV, were obtained from this separation (Figure 1). The chromatogram of Sample A (Angsa brand) was similar to Sample B (ABC brand), perhaps both samples contained similar components due to the same use of raw material (soybeans) and fermentation steps. Dry matters obtained from 5.0 $\mathrm{mL}$ soy sauce separation were presented in Tables 1 and 2. Their taste dilution factors for the umami intensity are presented in Table 1. The taste intensities of each fraction were comparable between Sample A and Sample B. The results from both samples can be averaged as a duplicate experiment. If these results compared to Japanese soy sauce fractions (Lioe et al., 2007), it is known that the highest umami taste intensity of fractions in this current study (TD factor 256) were 4 times intense compared to the fractions of Japanese soy sauce (the highest TD factor was $64)$, even though the dry matters concentrations shown in Table 2 were considerably 1.5 - 2 times higher than those of Japanese soy sauce. The result of Indonesian soy sauce fractions with umami TD factors is just reported in this study.

Fractions II and III are the main fractions, comprised of $29 \%$ and $65 \%$ of all dry matters in soy sauce, respectively. Fraction III had a relatively high absorbance at $254 \mathrm{~nm}$ which means that this fraction might contain a higher number of aromatic compounds, for example, L-phenylalanine and L-tyrosine, as observed previously in the research of Indonesian and Japanese soy sauces (Lioe et al., 2004; Lioe et al., 2007), which normally have a bitter taste (Kato et al., 1989). However this fraction from both soy sauce samples 
Table 1. Dry matters obtained from $5.0 \mathrm{~mL}$ of commercial salty soy sauces and umami taste dilution (TD) factors of chromatographic fractions tested at the same volume $(5.0 \mathrm{~mL})$

\begin{tabular}{crrcrcc}
\hline \multirow{2}{*}{ Fraction } & \multicolumn{3}{c}{ Dry matters (mg) } & \multicolumn{3}{c}{ TD factor of umami } \\
& \multicolumn{7}{c}{} & & & \\
\cline { 2 - 7 } & Sample A & Sample B & Average \pm SD & Sample A & Sample B & Average \pm SD \\
\hline I & 84.0 & 108.4 & $96.2 \pm 17.3$ & 32 & 32 & $32 \pm 0$ \\
II & 541.6 & 515.0 & $528.3 \pm 18.8$ & 128 & 64 & $96 \pm 45$ \\
III & 1398.1 & 1009.2 & $1203.7 \pm 275.0$ & 256 & 256 & $256 \pm 0$ \\
IV & 2.3 & 1.4 & $1.9 \pm 0.6$ & 4 & 4 & $4 \pm 0$ \\
\hline
\end{tabular}

Table 2. Percentage of dry matters in salty soy sauce fractions based on total dry matters $(\% \mathrm{w} / \mathrm{w})$ and total volume $(\% \mathrm{w} / \mathrm{v})$ of salty soy sauce

\begin{tabular}{|c|c|c|c|c|c|c|}
\hline \multirow[t]{2}{*}{ Fraction } & \multicolumn{3}{|c|}{$\begin{array}{c}\text { Dry matters } \\
(\% \mathrm{w} / \mathrm{w})\end{array}$} & \multicolumn{3}{|c|}{$\begin{array}{c}\text { Dry matters } \\
(\% \mathrm{w} / \mathrm{v})\end{array}$} \\
\hline & Sample A & Sample B & Average \pm SD & Sample A & Sample B & Average \pm SD \\
\hline I & 4.1 & 6.6 & $5.4 \pm 1.8$ & 1.7 & 2.2 & $1.9 \pm 0.3$ \\
\hline II & 26.7 & 31.5 & $29.1 \pm 3.4$ & 10.8 & 10.3 & $10.6 \pm 0.4$ \\
\hline III & 69.0 & 61.8 & $65.4 \pm 5.1$ & 28.0 & 20.2 & $24.1 \pm 5.5$ \\
\hline IV & 0.1 & 0.1 & $0.1 \pm 0.0$ & 0.05 & 0.00 & $0.0 \pm 0.0$ \\
\hline Soy sauce & & & & 40.6 & 32.7 & $36.6 \pm 5.6$ \\
\hline
\end{tabular}

had the highest umami intensity (Table 2), perhaps there is an interaction among components in the fraction to give the intense umami taste.

The four fractions also have relatively high absorbances at $214 \mathrm{~nm}$ which indicated the presence of compounds having peptide bonds and carboxylic groups, i.e., amino acids and peptides, in all four fractions. The pattern of chromatographic separation with this detection was similar to that of $254 \mathrm{~nm}$, therefore it is not shown. Free amino acids and/or peptides contained aromatic groups (Belitz et al., 2009; Pavia et al., 1996) were present mainly in Fractions I and III. Since gel filtration chromatography separated peptides earlier than free amino acids (Lioe et al., 2006), in this current study Fraction I was the peptide fraction, but had relatively low umami intensity compared to Fractions II and III. It is noted that Fractions II and III were salt fractions observed from the salty taste detected by the panel (at TD factors for salty taste 16 and 64, respectively). Therefore, salt was part of the dry matters of Fractions II and III reported in Table 1. Sodium salt was added to the product as appeared in the product composition. Soy sauce could contain 13\% w/v NaCl generally (Yokotsuka, 1981) or $13-16 \% \mathrm{w} / \mathrm{v} \mathrm{NaCl}$ in Japanese soy sauces (Lioe et al., 2007). However, the interaction between sodium chloride, free L-glutamic acid as well as hydrophobic amino acids, L-phenylalanine and L-tyrosine, might be occurred in this study as found in other soy sauce researches (Lioe et al., 2004; Lioe et al., 2007) and a sensory study (Lioe et al., 2005). Free amino acids could be found at $1.9-6.7 \%$ $\mathrm{w} / \mathrm{v}$ in Japanese soy sauce ultrafiltration fractions with molecular weights (MW) lower than 500 Da (Lioe et al., 2007), whereas total amino acids of Indonesian soy sauce at $131 \mathrm{mg} / \mathrm{g}$ or $13.1 \% \mathrm{w} / \mathrm{w}$ dry matters of the fraction with MW lower than 500 Da (Lioe et al., 2004).

\section{RP-HPLC profiles of soy sauce fractions}

RP-HPLC profiles of Fractions I to IV at $214 \mathrm{~nm}$ are shown in Figure 2. RP-HPLC profiles at $214 \mathrm{~nm}$ of the respective four fractions of Sample A and Sample B were similar. The profile of each fraction was different to each other, which indicated different components present in the fraction. The relative peak area percentages are presented in Table 3 . Fractions I and II had mainly earlier peaks with retention times between 2.3 and $3.5 \mathrm{~min}$ (Figure 2). The area of these peaks comprised more than $90 \%$ of the total peak area in Fractions I and II. This illustrates the percentage composition of the hydrophilic components in Fractions I and II. These peaks did not have any aromatic group due to the low absorbance at $254 \mathrm{~nm}$ observed in this study. These two fractions had a lower umami taste intensities compared to Fraction III.

Fraction III contained both earlier and later peaks, which were eluted between 3.0 to $6.0 \mathrm{~min}$. One of the peaks was to contain an aromatic group due to relatively high absorbance at $254 \mathrm{~nm}$ (Table 3). If looking at umami intensities in Tables 1 and the characteristic of components in Table 3, as well as HPLC profiles in Figure 2, the hydrophilic components in Fractions II and hydrophilic as well as hydrophobic components in Fraction III, were the main umami components of Sample A and Sample B. It is interesting that Fraction III of the two soy sauce samples which contained hydrophilic, aromatic and nonaromatic hydrophobic components was rated to have the highest umami taste intensity. This fact emphasized that besides hydrophilic components, hydrophobic components could also contribute to the high umami intensity of the commercial soy sauce samples. The presence of those components in soy sauce has also been predicted in other soy sauce study in a different way (Jakobi et al., 2017). 


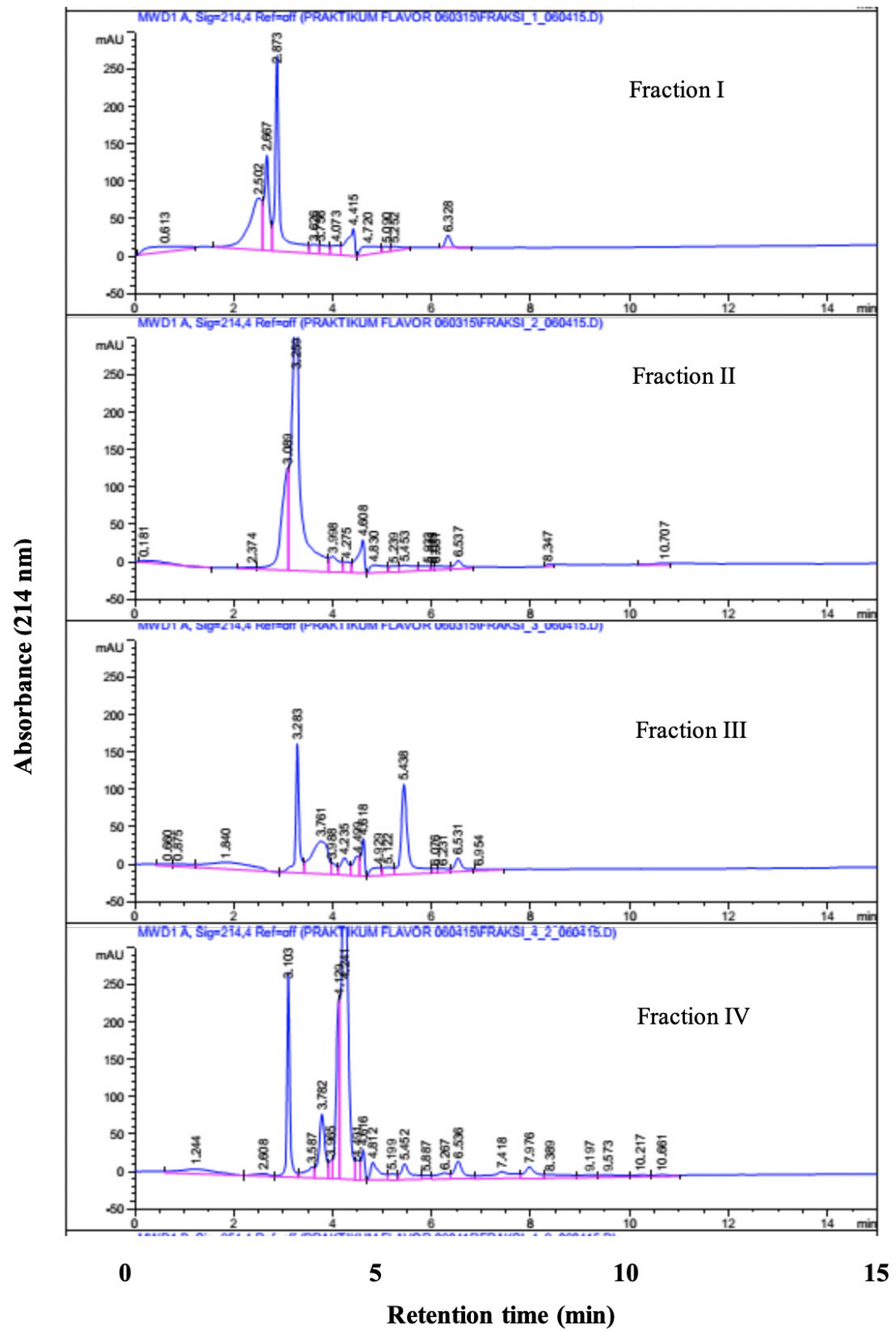

Figure 2 - RP-HPLC profiles of commercial salty soy sauce fractions (Sample A) using HPLC condition as follows: C-18 column (i.d. $4.6 \times 150 \mathrm{~mm}, 5 \mu \mathrm{m}$ particle size), an isocratic elution of acetonitrile in Milli-Q water (0-20 min) at 20\%, detection at UV $214 \mathrm{~nm}$ using MWD detector, injection volume $20 \mu \mathrm{L}$. The concentrations of dry matters in the solutions injected into HPLC were ranged between 78 to $186 \mu \mathrm{g} / \mathrm{mL}(130 \mu \mathrm{g} / \mathrm{mL}$ in average). The results of Sample B were similar to those of Sample A.

Table 3. Percentage of area relative (\%) of peaks detected by RP-HPLC (detection at UV $214 \mathrm{~nm}$ ) of four chromatographic fractions

\begin{tabular}{cccccc}
\hline $\begin{array}{c}\text { Retention } \\
\text { time (min) }\end{array}$ & Fraction I & Fraction II & $\begin{array}{c}\text { Fraction } \\
\text { III }\end{array}$ & Fraction IV & $\begin{array}{c}\text { Predicted } \\
\text { components }\end{array}$ \\
\hline $2.3-2.9$ & 91 & & & & Hydrophilic \\
$3.0-3.5$ & & 92 & 38 & 13 & Hydrophilic \\
$3.6-4.5$ & 7 & 20 & 85 & $\begin{array}{c}\text { Aromatic } \\
\text { hydrophobic* }\end{array}$ \\
$4.6-6.0$ & & 41 & & $\begin{array}{c}\text { Non-aromatic } \\
\text { hydrophobic }\end{array}$ \\
\hline
\end{tabular}


The hydrophilic amino acids such as umami amino acids ( L-glutamic acid and L-aspartic acid), and sweet amino acids (L-serine and L-threonine), were the main amino acids in Japanese and Indonesian soy sauces and contributed to the intense umami taste of soy sauces (Lioe et al., 2004; Lioe et al., 2007). The hydrophilic compounds were also found in Korean soy sauce (Kim et al., 2017) and Chinese soy sauce (Zhang et al., 2016). In this current study, Fractions II and III might contain the umami and sweet amino acids.

Hydrophilic peptides might be present in Fraction I as a consequence of gel filtration (Figure 2 and Table 3), and its contribution to the umami taste of soy sauce could not be neglected (Table 1). The peptides which impart umami taste have been found in other researches (Kato et al., 1989; Nishimura and Kato, 1989; Zhuang et al., 2016).

Fraction IV contained mainly hydrophobic components which are commonly tasted bitter (Kato et al., 1989), however, this fraction still had a lesser extent of umami taste. Perhaps, this is due to the presence of hydrophilic components eluted at 3.0-3.5 min. In fact, the bitter taste was not perceived in the original salty soy sauce, but through this study, the bitter taste was found in one fraction, Fraction IV. This study gives an insight that the presence of hydrophilic components together with hydrophobic components, as a consequence of soy protein breakdown during fermentation of soy sauce, was related to the intense umami taste of soy sauce.

\section{CONCLUSION}

Indonesian commercial salty soy sauce has intense umami. The intensity of the most intense umami fraction obtained by chromatography separation could reach 4 times higher than that of Japanese soy sauce. Hydrophilic as well as hydrophobic components originated from soy protein breakdowns, which might be related to the umami taste.

\section{REFERENCES}

Apriyantono, A., Husain, H., Lie, L., Judoamidjojo, M. and PuspitasariNienaber, N.L. 1999. Flavor characteristics of Indonesian soy sauce (kecap manis). In "Flavor chemistry of ethnic foods". ed. F. Shahidi, and C.T. Ho. Kluwer Academic/Plenum Publishers, New York. p. 1531.

Apriyantono, A., Setyaningsih, D., Hariyadi, P. and Nuraida, L. 2004. Sensory and peptide characteristics of soy sauce fractions obtained by ultrafiltration. In "Quality of fresh and processed foods". ed. A.M. Spanier, F. Shahidi, C.T. Ho, and T. Braggin. Kluwer Academic/ Plenum Publishers, New York. p. 1-14.

Belitz, H.D., Grosch, W. and Schieberle, P. 2009. "Food chemistry". Springer, Berlin Heidelberg, Germany.

Carpenter, R.P., Lyon, D.H. and Hasdell, T.A. 2000. "Guidelines for sensory analysis in food product development and quality control". Aspen Publishers Gaithersburg, Maryland.

Dang, Y., Gao, X., Ma, F. and Wu, X. 2015. Comparison of umami taste peptides in water-soluble extractions of Jinhua and Parma hams. LWT-Food Science and Technology. 60:1179-1186.

Frank, O., Ottinger, H. and Hofmann, T. 2001. Characterization of an intense bitter-tasting $1 \mathrm{H}, 4 \mathrm{H}$-quinolizinium-7-olate by application of the taste dilution analysis, a novel bioassay for the screening and identification of taste-active compounds in foods. Journal of Agriculture and Food Chemistry. 49:231-238.
Istiqamah, A., Lioe, H.N. and Adawiyah, D.R. 2019. Umami compounds present in low molecular umami fractions of asam sunti-A fermented fruit of Averrhoa bilimbi L. Food Chemistry. 270:338-343.

Jakobi, V., Salmen, P., Paulus, M, Toal, M. and Rosenhahn, A. 2017. Compositional fingerprint of soy sauces via hydrophobic surface interaction. Food Chemistry. 218:256-260.

Kato, H., Rhue, M.R. and Nishimura, T. 1989. "Role of free amino acids and peptides in food taste". In: "Flavor chemistry: Trends and developments". ed. R. Teranishi, R.G. Buttery, and F. Shahidi. American Chemical Society, Washington. p. 158-174.

Kim, Y., Kim, E.Y., Son, H.J., Lee, J.J., Choi, Y.H. and Rhyu, M.R. 2017. Identification of a key umami-active fraction in modernized Korean soy sauce and the impact thereof on bitter-masking. Food Chemistry. 233:256-262.

Lioe, H.N., Apriyantono, A., Takara, K., Wada, K., Naoki, H. and Yasuda, M.Y. 2004. Low molecular weight compounds responsible for savory taste of Indonesian soy sauce. Journal of Agriculture and Food Chemistry. 52:5950-5956.

Lioe, H.N., Apriyantono, A., Takara, K., Wada, K. and Yasuda, M.Y. 2005. Umami taste enhancement of MSG/NaCl mixtures by subthreshold L- $\alpha$-aromatic amino acids. Journal of Food Science. 70:401-405.

Lioe, H.N., Takara, K. and Yasuda, M. 2006. Evaluation of peptide contribution to the intense umami taste of Japanese soy sauces. Journal of Food Science. 71:277-283.

Lioe, H.N., Wada, K., Aoki, T. and Yasuda, M. 2007. Chemical and sensory characteristics of low molecular weight fractions obtained from three types of Japanese soy sauce (shoyu) - koikuchi, tamari, and shiro shoyu. Food Chemistry. 100:1669-1677.

Lioe, H.N., Kinjo, A., Yasuda, S., Kuba-Miyara, M., Tachibana, S. and Yasuda, M. 2018. Taste and chemical characteristics of low molecular weight fractions from tofuyo-Japanese fermented soybean curd. Food Chemistry. 252:265-270.

Nishimura, T. and Kato, H. 1988. Taste of free amino acids and peptides. Food Review International, 4:175-194.

Ottinger, H. and Hofmann, T. 2003. Identification of the taste enhancer alapyridaine in beef broth and evaluation of its sensory impact by the taste reconstitution experiments. Journal of Agriculture and Food Chemistry. 51:6791-6796.

Pavia, D.L., Lampman, G.M. and Kriz, G.S. 1996. "Introduction to spectroscopy, 2nd Edition". Harcourt Brace College Publishers, Philadelphia, USA.

Röling, W.F.M., Timotius, K.H., Prasetyo, A.B., Stouthamer, A.H. and Van Verseveld, H.W. 1994. Changes in microflora and biochemical composition during the baceman stage of traditional Indonesian kecap (soy sauce) production. Journal of Fermentation and Bioengineering. 77:62-70.

Röling, W.F.M., Apriyantono, A. and Van Verseveld, H.W. 1996. Comparison between traditional and industrial soy sauce (kecap) fermentation in Indonesia. Journal of Fermentation and Bioengineering. 81:275-278.

Tamam, B., Syah, D., Suhartono, M.T., Kusuma, W.A., Tachibana, S., Lioe, H.N. 2019. Proteomic study of bioactive peptides from Tempe. Journal of Bioscience and Bioengineering. 128:241-248.

Yokotsuka, T. 1981. Recent advances in shoyu research.. In "The quality of foods and beverages" ed. G. Charalambous and G. Inglett. Academic Press, New York. p. 171-96.

Zhang, L., Zhou, R., Cui, R., Huang, J. and Wu, C. 2016. Characterizing soy sauce moromi manufactured by high-salt dilute-state and low-salt solid-state fermentation using multiphase analyzing methods. Journal of Food Science. 81:2639-2646.

Zhuang, M., Lin, L., Zhao, M., Dong, Y., Sun-Waterhouse, D., Chen, H., Qiu, C. and Su, G. 2016. Sequence, taste and umami-enhancing effect of the peptides separated from soy sauce. Food Chemistry. 206:174181. 